\title{
PEDAGOGICAL METHODS AND THE DEVELOPMENT TEACHING PROCESS IN CLASS
}

\author{
MILIKA ENVER NURKA \\ University “Ismail Qemali” Vlora, Albania“ \\ Deparment of Teaching and Albanian Education,
}

\begin{abstract}
Teaching methods in instruction developed as a replacement for"general pedagogical methods" since specific subjects require different approaches (e.g. the same teaching method cannot be efficiently applied to foreign language and physics classes). Teaching methods are a theoretical and practical system which in a scientifically established way describes and proscribes effective teaching methods of a specific subject or a group of related subjects.
\end{abstract}

Teaching methods (methodology) of a certain subject will use didactic knowledge about the individualization of the instructional process, teaching methods and didactical principles, the types of instruction and organization of instruction. In addition, the choice of appropriate teaching method and instruction in a specific situation will be influenced by the scientific and expert field of a certain subject, as well as the characteristics of the participants (their psychosocial development, previous knowledge, interests etc). The basic question resulting from the previous definition of methodology or teaching methods is whether universal or general methodology in distance education is possible. In distance education general principles and different educational methods can be formulated, but every specific subject or area in distance education should use theoretical and practical principles of methodology developed especially for this subject or field. General didactic principles and available educational methods for online education should in practice always be adapted to specific methodical teaching approaches for a specific subject or field.

Education is a process by which human beings and societies reach their fullest potential. Education is critical for promoting sustainable development and improving the capacity of people to address environment and development issues. It is also critical for achieving environmental and ethical awareness, values, and skills consistent with sustainable development and effective public participation in decision-making. Policy-makers concerned with children's access and participation in education would find this indicator. When investigating or reporting on learning standards, it is important to know how they were developed, what knowledge and skills they describe, and how they are actually used in schools. To recommend ways in which concern for the environment may be translated into greater co-operation among developing 
countries and between countries at different stages of economic and social development and lead to the achievement of common and mutually supportive objectives which take account of the interrelationships between people, resources, environment and development;

\section{JEL Classification System: SI, S2, S3, N0, N1, N2, N3, O1, O2, O3}

\section{GENERAL INFORMATION AND PURPOSE OF THIS PAPER RESEARCH:}

It is especially important to be well acquainted with different education methods and teaching approaches in order to apply them appropriately in order to achieve educational objectives. Among the most wide spread types of instruction the following can be pointed out:

- transmission instruction and direct teaching (informing, describing, explaining, training, asking questions, monitoring the questions, intervening);

- heuristic instruction and teaching through conversation (asking questions, dialogue, group discussions);

- pair work and cooperative grouping (joint assignments, analyses, evaluations, problem solving, creative techniques, decision making etc);

- problem teaching (identifying and defining a problem, setting hypotheses, gathering data, generating the solution, evaluating the possibilities, selecting the solution, concluding and applying this in practice);

- programmed instruction (division of content into smaller units, tasks and questions which stimulate relevant activities, and feedback about the users and their results).

Programmed instruction is a system of theoretical concepts and different technical forms of programmed instruction which enable simulated delivery of instruction so as to achieve a 1:1 student:" instructor" ratio (i.e. a technical system simulating an instructor). Instead of traditional instruction in which there is one teacher and several students and where a complete individualization of the educational process is impossible, in programmed learning individual teaching is "multiplied" by using the so-called programmed textbooks, computerbased instruction or learning management systems (LMS). Research shows that programmed teaching is usually more successful than traditional instruction, taking into consideration short-term and long-term memory of educational content, as well as time spent on learning.With programmed learning participants are guided by questions and tasks which stimulate their inner mental activity, while the possibility to check the correct answer influences the so-called self-confirmation which causes the feeling of extrinsic and intrinsic reward and motivation. The use of programmed learning is especially useful in distance education and computer-based instruction.Source: SNARC Teaching 2016 
II. Sustainable development is not a new concept. It means living in harmony with the nature in full recognition of the needs of all other species. It is no just "the survival of the fittest", we must help even the weakest of the species to survive because each species has a role to play that is ultimately beneficial to the earth and all its human population. Our forefathers preached us the need to coexist with the environment in a balanced manner. Source: Our Common Future: The World Commission on Environment and Development, Oxford: Oxford University Press].

Any development activity can be sustainable, if it is "a dynamic process which enables all people to realize their potential and to improve their quality of life, in ways which simultaneously protect and enhance the Earth's life support systems". Source: (Forum for the Future, Annual Report 2000).

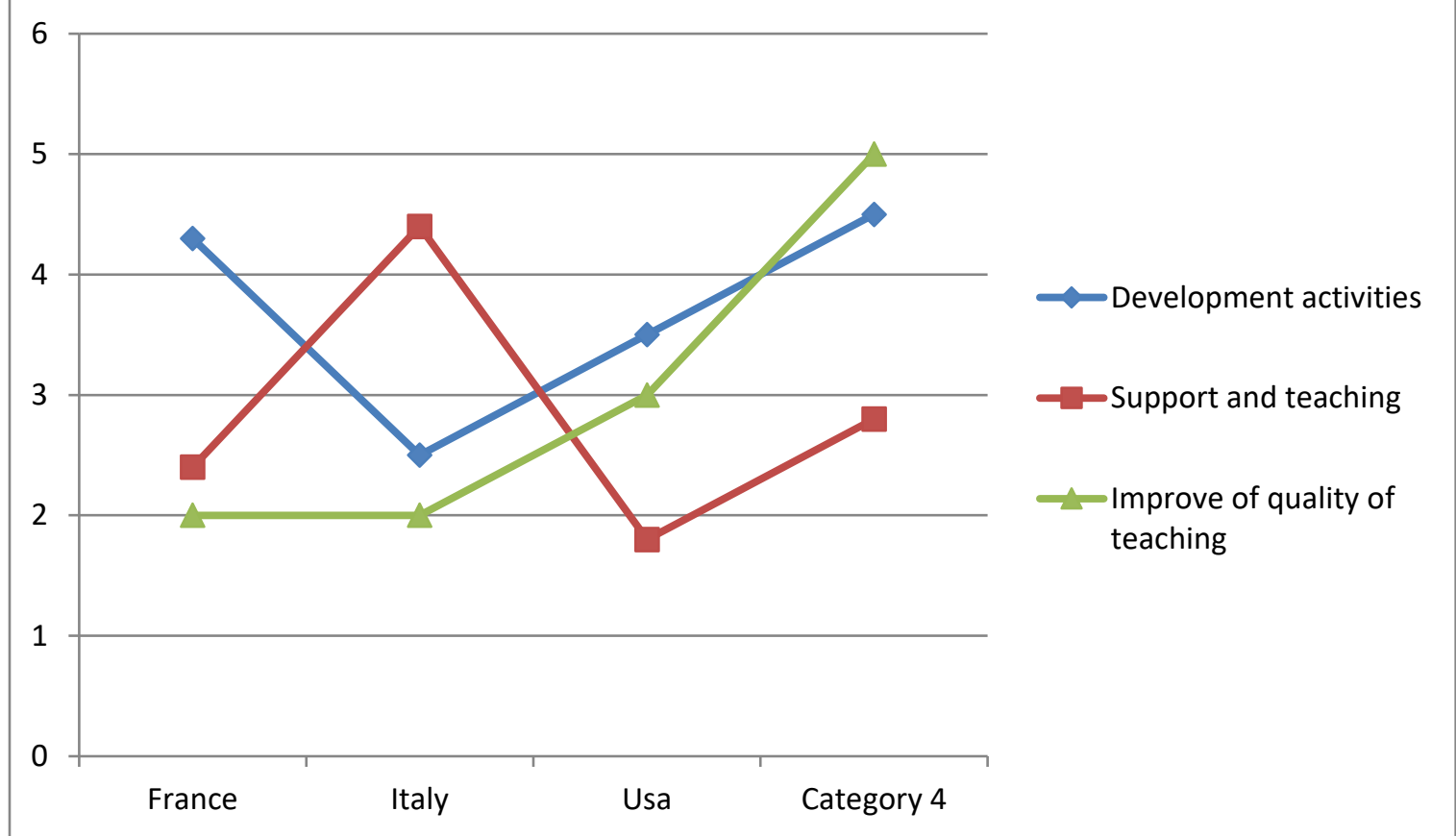

Source: (Forum for the Future, Annual 2014

It should be noted that, after substantial initial investment and excitement about the possibilities of e-education, the results of conducted evaluation of this kind of training showed that there are many sources of difficulties and dissatisfaction of the online instruction or course participants. Evaluation also emphasized that on the average a relatively large number of participants (sometimes over 25\%) do not finish the online education they started (to check this data search the web using expressions» dropout rate" and "e-learning" ). It became obvious that only putting course content on the Internet/web, without using appropriate pedagogical models and principles, as well as without sufficient share of appropriate communication types between participants and with the instructor, are not enough to fulfills the educational goals if the participants are not sufficiently independent. The development has become the cornerstone of 
development planning today and has also become a principal tool of negotiation in international aid packages to the countries.Appropriate policies and measures could then be adopted to address problems of grade repetition and drop-out as well as bottlenecks with regard to retention in school.

The reason for pairing standards with indicators is that while an indicator is the measurement itself, a standard defines the point for that particular measurement which must be reached or maintained. The education standard and indictor information is also important to secure funding from donors and potential donor countries and organizations.

1. If, for example, all of the countries in region A are reporting over 100 per cent enrolment and/or 100 per cent of qualified teachers, it would appear as if these countries are doing very well as regards access to and quality of education.

\section{Indicators of Teaching}

Ask questions and seek out specific feedback

Guiding students toward self-reflection

Targeted help / instruction in specific areas of reading

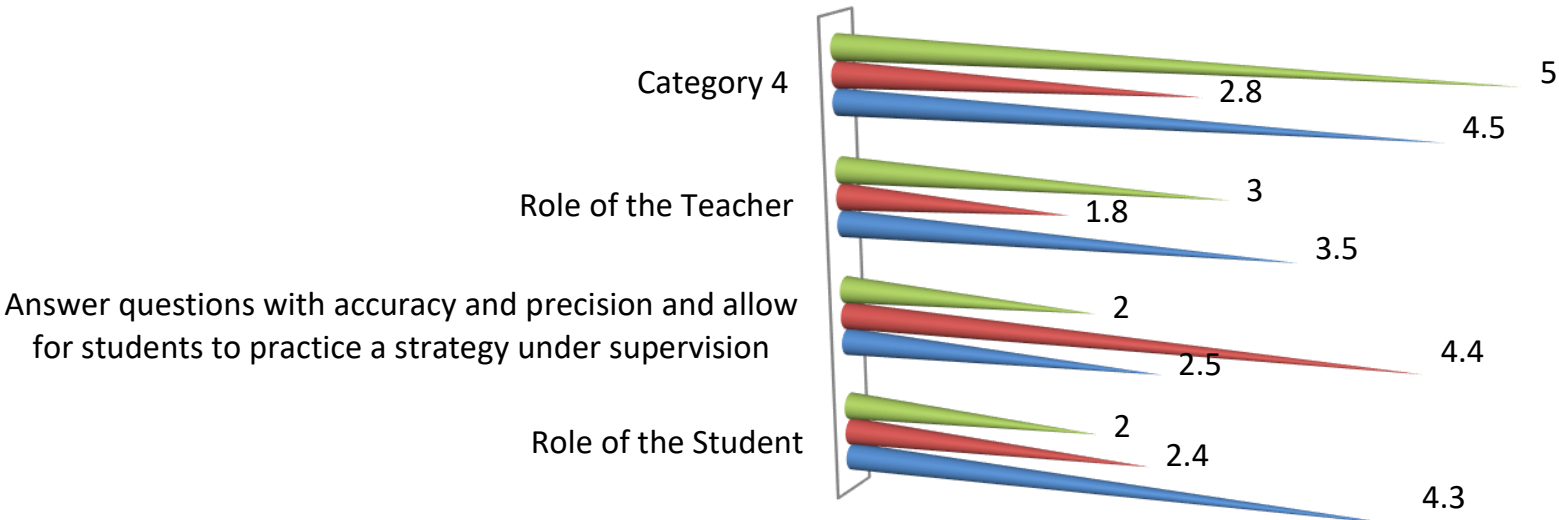


Standards and Indicators and Other Key Terms 1: The data collected can also be used to seek out new and strengthen existing partnerships. If UNHCR notices for example that there is a very low percentage of 15-24 year olds enrolled in training programmed, then UNHCR and relevant partners can use this information to address this gap and strengthen non formal education activities.

\section{LITERATURE REVIEW AND HYPOTHESES}

Modern corporations and state institutions in developed countries have accepted e-education as a way to educate larger groups of employees in less time and reducing the use of various resources. In many countries the employees of modern companies will take at least $60-80 \%$ of in-job training courses online, without having to travel and postpone urgent or priority tasks.

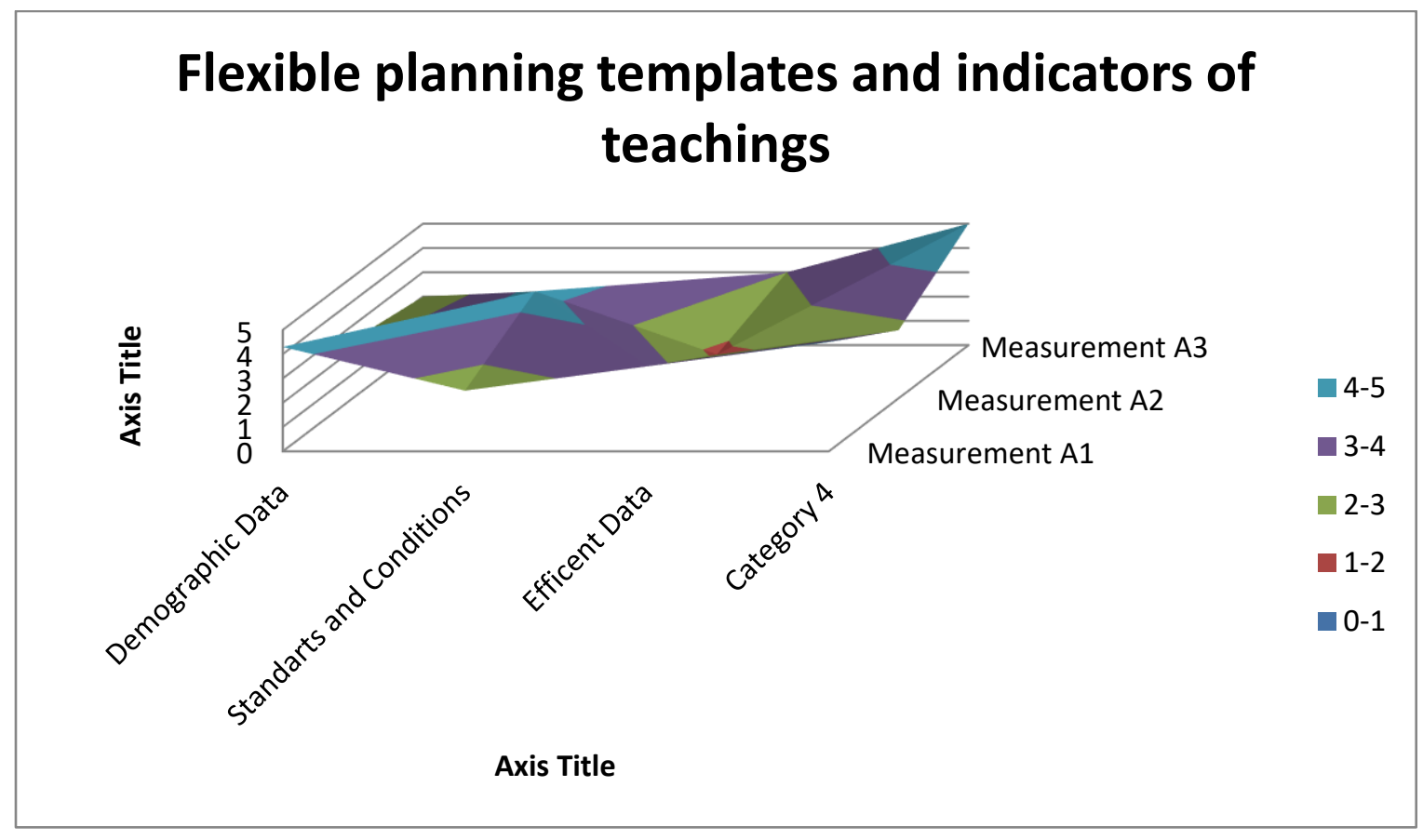

In this graph:Percentages and rates are particularly useful in calculating indicators, as opposed to absolute values, which are the numbers that have not been divided by a total and are not part of a fraction. To calculate the percentage of female teachers you divide the numerator, the total number of female teachers by the denominator, the total number of teachers. 


\section{HYPOTHESES AND THE AIM OF THIS PAPER RESEARCH}

\section{Teaching Methods}

Many initial distance education web applications consisted solely of making theinstructional materials available online. In doing so, appropriate methods of online education and communication and multimedia capabilities of the Internet and webwere usually not used.

Designing a distance education system for a course or a subject requires a detailed definition of the educational goals and objectives beforehand.

Source:https://www.carnet.hr/referalni/obrazovni/en/mkod/teaching

2. Educational conditions set certain limits and provide possibilities, and are defined by the following questions which need to be answered during the preparation for online instruction:

3. Who are the participants and what are their characteristics?

4. What changes in the participants do we want to achieve with online education?

5. What are the technological, organizational and other possibilities and limitations?

6. What us the level of participants' previous expert knowledge and skills?

7. What are the participants' expectations and what is their motivation?

8. To what extent do the participants use information technologies?

9. What knowledge, skills and other capabilities should the participants acquire?

10. How will the participants' knowledge be measured and what are the criteria for their success?

11. Should a curriculum be developed and what subjects/courses will be included in it?

Technological possibilities in design of online educational system are related to available methods of presentation of educational content, the communication with the participants, as well as between the participants, and the Internet connection speed that the participants have at their disposal.

Organizational possibilities are related to the way and quality of the development of educational 
materials, as well as to the number and ability of the teachers, instructors, coaches and/or mentors who will participate in distance education.

\section{Source: https://www.carnet.hr/referalni/obrazovni/en/mkod/teaching}

Technological and organizational possibilities, combined with educational conditions and goals, determine the ways distance education is delivered in comparison to traditional instruction : (a) traditional instruction dominates, supplemented by online education from time to time only;

Blended learning is an approach which combines traditional instruction and online education. Blended learning is the most appropriate choice when the participants are not sufficiently independent and motivated to use a distance education system, when they should be previously trained and prepared for online education, as well as in cases when the unavoidable/obligatory instruction or courses (in the classroom, laboratory, training centre etc.) should be supplemented with more modern sources and methods of acquiring knowledge.Source: https://www.carnet.hr/referalni/obrazovni/en/mkod/teaching

The concept of ESD developed largely from environmental education, which has sought to develop the knowledge, skills, values, attitudes and behaviors' in people to care for their environment. The aim of ESD is to enable people to make decisions and carry out actions to improve our quality of life without compromising the planet. It also aims to integrate the values inherent in sustainable development into all aspects and levels of learning. 


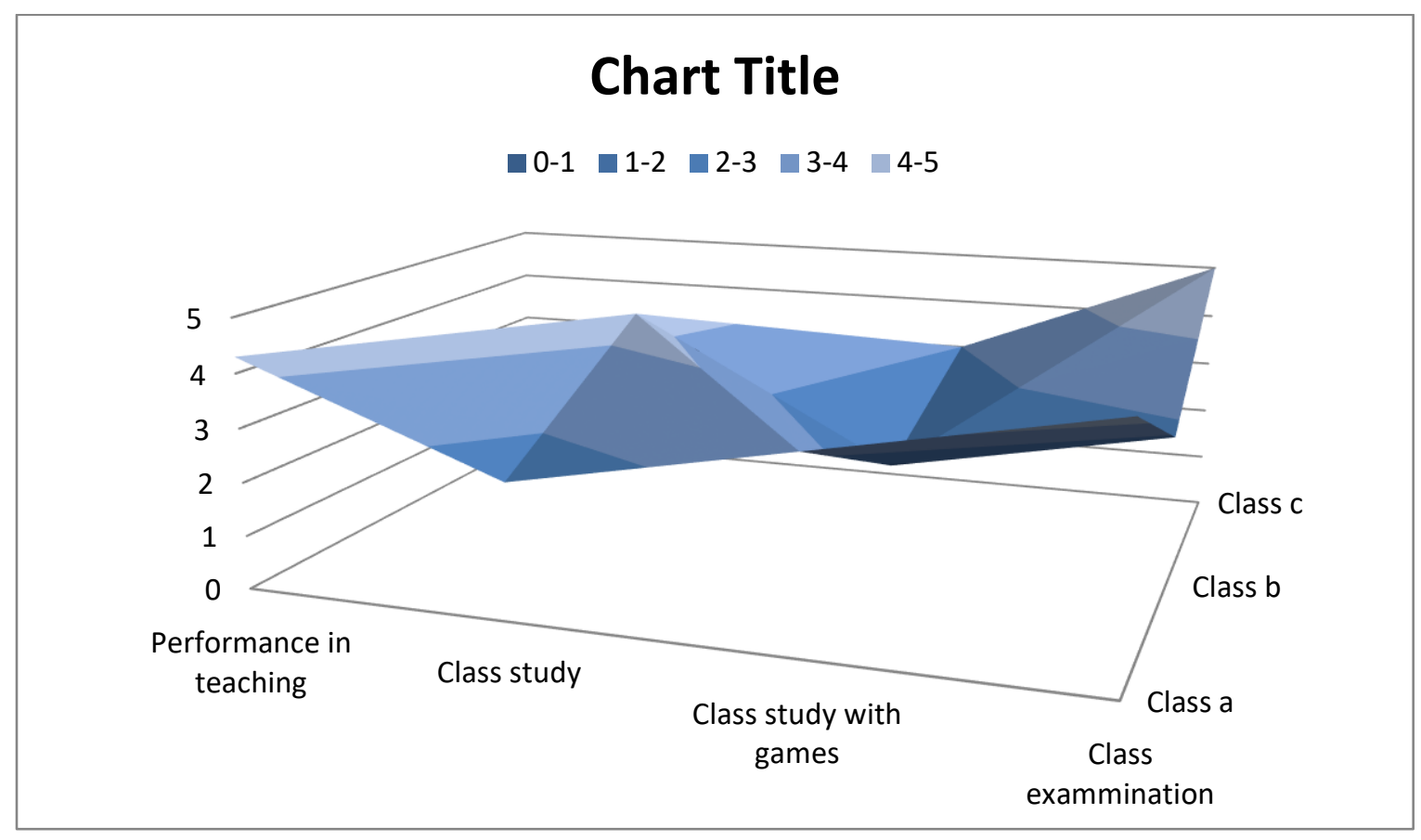

COMMUNICATION IN YOUR CLASS: Pedagogical approaches and methods are important factors for success in online education. Avoid the mistake of insufficient planning of teaching methods. Do not put the content on the web first and then think how to apply a certain teaching method. Devote at least $10-20 \%$ of the development time of an online educational system in a course/subject to research activities and plan the pedagogical methods, bearing in mind the characteristics and educational needs of the participants as well as the available resources.

a) Employ a variety of educational methods, such as literature, art, drama and debate to illustrate the processes.

b) Allow learners to participate in decision-making on the design and content of educational programmed.

c) Address local as well as global issues, and avoid jargon-ridden language and terms.

d) Look to the future, ensuring that the content has a long-term perspective and uses medium and long-term planning.

e) The teacher is prepared and knowledgeable of the content and effectively maintains students' on-task behavior; 
f) The teacher keeps current on instructional knowledge and seeks and explores changes in teaching behaviors that will improve student performance.

\section{CONCLUSIONS}

Traditionally the higher education system in Albania has comprised the university sector, the technological sector and the colleges of education, all of which are autonomous and selfgoverning, although substantially funded by the state. In recent years, a number of independent private colleges have appeared and grown although there has been limited progress in some third level institutions in addressing the issue of a whole school approach to ESD. On the other hand, many third level institutions have introduced courses in sustainable development: the Masters of Science in Albania.Here are several options to guide the participants through learning and to manage the educational process.

In some cases the lecturer/instructor manages the work of the participants to a high degree as well as provides educational topics, content and tasks, sets the deadlines and schedules work, helps and guides the participants, as well as evaluates them and communicates with them intensively. In other cases the participants are more independent and work alone in the L@ MS system, where they pace the tempo, set the order of educational content that they will learn as well as set the intensity of communication with the instructor/mentor.

Pedagogical methods in distance education are related to different types of individual and group work. When choosing teaching and learning methods, bear in mind the number and characteristics of the participants, the available technology and educational goals.

\section{REFERENCES}

- International Standard Classification of Education 1997, UNESCO (b) Internet site: http://www.uis.unesco.org (UNESCO Institute for Statistics) Schools need principals who strive to ensure the quality of instruction in their schools (Harris, 2007; 
ISSN 2661-2666( Online) International Scientific Journal “Monte” DOI : $\underline{10.33807 / \text { monte.1.201904244 }}$ ISSN 2661-264X (Print)

- Principals of high-achieving schools expect teachers and students to meet the schools' goals (Leithwood \& Riehl, 2003).The Education for All (EFA) Global Monitoring Reports (GMR), UNESCO. The Millennium Development Goals Report 2006, United Nations.

- Principals of high-achieving schools are confident that their schools can meet their goals (Cotton, 2003).

- Principals who focus on school improvement have more effective schools (Shen \& Hsieh, 1999). 